\title{
Factors associated with pain in nonsurgically treated rotator cuff tears $-A$ study with magnetic resonance imaging
}

\author{
Yoshihiro Nakamura ${ }^{1 *}$ D, Shin Yokoya ${ }^{2}$, Yohei Harada ${ }^{3}$, Mitsuo Ochi ${ }^{4}$ and Nobuo Adachi ${ }^{5}$
}

\begin{abstract}
Background: In rotator cuff tears, some cases become asymptomatic with nonsurgical treatment, others remain symptomatic. The purpose of this study was to identify factors associated with pain in nonsurgically treated rotator cuff tears using magnetic resonance imaging (MRI).

Methods: In total, 108 shoulders diagnosed with supraspinatus (SSP) tendon tears using MRI were nonsurgically treated, and MRI was repeated after more than a year. The patients were divided into pain or improvement group according to whether the pain persisted or disappeared. Bursal fluid accumulation; SSP tendon retraction; subscapularis (SSC) tendon tears; infraspinatus (ISP) tendon tears; and Goutallier classification into SSC, SSP, and ISP were included as evaluation factors. Predictive factors for persistent pain on initial MRI and factors associated with persisting pain after nonsurgical treatment on repeat MRI were statistically analyzed using multivariate logistic regression analysis.
\end{abstract}

Results: The improvement group showed a significant decrease in bursal fluid accumulation compared with the pain group ( $p<0.01)$. SSC tendon tears $(\mathrm{OR}, 4.42 ; 95 \% \mathrm{Cl}, 1.16-16.9 ; \mathrm{P}=0.03)$ on initial MRI were significantly associated with persistent pain. Bursal fluid accumulation $(\mathrm{OR}, 2.44 ; 95 \% \mathrm{Cl}, 1.18-5.07 ; \mathrm{P}=0.02)$ and SSC tendon tears $(\mathrm{OR}, 2.25$; $95 \% \mathrm{Cl}, 1.15-4.39 ; \mathrm{P}=0.02$ ) on repeat $\mathrm{MRI}$ were significantly associated with persistent pain.

Conclusions: Bursal fluid accumulation decreased when pain improved. The involvement of SSC tendon tears can serve as a predictive factor for persistent pain. Pain may persist although patients with rotator cuff tears including SSC tendon tears are nonsurgically treated.

Level of evidence: Level IV case-control study

Keywords: Rotator cuff tear, Nonsurgical treatment, Magnetic resonance imaging, Pain, Subscapularis tendon tear

\section{Background}

A rotator cuff tear is a common cause of pain and disability of the shoulder among adults. Some rotator cuff tears are symptomatic, whereas others are asymptomatic $[1,2]$. Treatment strategy for rotator cuff tears remains unclear [3]. Because nonsurgical treatment often improves the pain and range of motion in patients with symptomatic rotator cuff tears [4], it is typically preferred as the first-line treatment $[5,6]$. Conversely, surgical treatment is occasionally required when symptoms do not improve. Success rates of nonsurgical treatment

\footnotetext{
* Correspondence: nakamurayoshihiro0419@gmail.com

1Department of Orthopaedic Surgery, Chugoku Rosai Hospital, 1-5-1, Tagaya, Hiro, Kure City, Hiroshima 737-0193, Japan

Full list of author information is available at the end of the article
}

have been reported to vary widely, ranging 33-82\% [6-10]. Itoi et al. reported that patients with complete rotator cuff tears, and who had been treated conservatively, exhibited unsatisfactory results with limited active abduction angle and muscle weakness on abduction on first examination [8]. Tanaka et al. reported that an intact intramuscular tendon of the supraspinatus (SSP), showing little or no atrophy of the SSP muscle, with negative impingement signs, and with preserved motion in external rotation are factors related to the successful outcome of conservative treatments [6]. Boorman et al. reported that the rotator cuff quality-of-life index was predictive of the outcome of non-operative treatment in patients with a chronic full-thickness rotator cuff tear [11]. Dunn et al. reported that patient expectations

(c) The Author(s). 2019 Open Access This article is distributed under the terms of the Creative Commons Attribution 4.0 International License (http://creativecommons.org/licenses/by/4.0/), which permits unrestricted use, distribution, and 
regarding the role of rehabilitation were the strongest predictor of surgery and other factors associated with surgery were higher activity level and not smoking [12]. However, a failure of nonsurgical treatment was defined if the patient elected to have surgery after nonsurgical treatment in most previous studies. There may be a potential selection bias because some patients do not want to undergo surgery whereas others want to undergo surgery and failure of nonsurgical treatment is determined relatively early in previous studies. It is unclear about the difference between cases that become asymptomatic with nonsurgical treatment and cases that nonsurgical treatment is continued as symptomatic. Although most rotator cuff tears occur in the SSP tendon, other tendons of the rotator cuff may also be torn. In addition, the degree of fatty infiltration of rotator cuff muscles varies. The effect of nonsurgical treatments may depend on the severity of the rotator cuff tears. Therefore, the purpose of this study was to identify the factors associated with persisted pain in nonsurgically treated rotator cuff tears using magnetic resonance imaging (MRI).

\section{Methods}

\section{Study population}

From 2010 to 2014, all symptomatic patients diagnosed with full-thickness SSP tendon tears, regardless of whether infraspinatus (ISP) and subscapularis (SSC) tendon tears existed or not on MRI, were nonsurgically treated using steroids or hyaluronic acid injections and anti-inflammatory analgesics. Patients were recommended for surgery when symptoms persisted after nonsurgical treatment for at least 3 months. Patients who rejected to undergoing surgery were continued to be nonsurgically treated. The treatment was terminated if subjective symptoms disappeared by nonsurgical treatment, and the patients were regularly followed-up. Patients were reexamined using MRI at more than 1 year after the initial MRI. Patients who underwent surgery; patients who could not be followed-up; and patients with a history of surgery, fracture, osteoarthritis, or purulent arthritis of ipsilateral shoulder joints; patients with rheumatoid arthritis; and patients suspected to have neurological disease or cervical spine disease, such as cervical spondylotic amyotrophy, were excluded from this study. In total, 97 patients (108 shoulders), including 49 males (55 shoulders) and 48 females 53 shoulders), with a mean age of $68.9 \pm 8.1$ (range, 44-84) years, were enrolled. Mean follow-up period was $22.6 \pm 12.4$ (range, 1254) months. The patients were divided into pain group and improvement group. Pain group consisted of patients that pain persisted until repeat MRI and required continued nonsurgical treatments such as steroids, hyaluronic acid injections, and/or anti-inflammatory analgesics. Improvement group consisted of patients that became asymptomatic and the treatment was terminated before repeat MRI. Finally, 63 patients (67 shoulders; mean age, $69.4 \pm 8.2$ years; males, 32 shoulders; females, 35 shoulders; mean follow-up period, $21.4 \pm 10.8$ months) were included in the pain group and 38 patients (41 shoulders; mean age, $68.1 \pm 8.1$ years; males, 23 shoulders; females, 18 shoulders; mean follow-up period, $24.9 \pm 14.5$ months) were included in the improvement group.

\section{MRI}

MRI examinations were performed using a 1.5 Tesla scanner (Sigma; GE Medical Systems, Milwaukee, WI, USA or EXCELART Vantage; Toshiba Medical Systems, Tochigi, Japan). The patients were rested in a supine position with the affected arm toward the side of the body, with the palm of the hands facing upward, for the imaging of the shoulder joints. The imaging protocol included the following sequences (Sigma/EXCELART Vantage): oblique coronal T2-weighted imaging [repetition time (TR), 5000/3200 ms; echo time (TE), 90/90 ms; slice thickness, $4.5 / 4 \mathrm{~mm}$; slice gap, $0.5 / 0.8 \mathrm{~mm}$; field of view (FOV), 18/20 cm; matrix, $320 \times 288 / 240 \times$ 240 pixels; and echo train length (ETL), 18/23]; axial T2-weighted imaging [TR, 4500/3200 ms; TE, 90/90 ms; slice thickness, $4.5 / 4 \mathrm{~mm}$; slice gap, $0.5 / 0.8 \mathrm{~mm}$; FOV, $18 / 20 \mathrm{~cm}$; matrix, $320 \times 256 / 240 \times 240$ pixels; and ETL: 20/23]; oblique sagittal T1-weighted imaging [TR, 850/ $700 \mathrm{~ms}$; TE, $10.2 / 15 \mathrm{~ms}$; slice thickness, $4.5 / 4 \mathrm{~mm}$; slice gap, 0.5/0.8 mm; FOV, 18/20 cm; matrix, $288 \times 192 / 224$ $\times 320$ pixels; and ETL, 2/5]; and oblique sagittal T2-weighted imaging [TR, 5000/4200 ms; TE, 90/90 ms; slice thickness, $4.5 / 3 \mathrm{~mm}$; slice gap, $0.5 / 0 \mathrm{~mm}$; FOV, $18 /$ $14 \mathrm{~cm}$; matrix, $320 \times 256 / 384 \times 269$ pixels; and ETL, 20/ 12]. The same MRI scanner that was initially used was used for the repeat MRI.

\section{Evaluation}

Bursal fluid accumulation; SSP tendon retraction; SSC tendon tears; ISP tendon tears; and Goutallier classification in SSC, SSP, and ISP were included as evaluation factors. Subcoracoid-subacromial-subdeltoid bursal fluid accumulation was evaluated. The volume of fluid was graded as follows: grade 0, bursal fluid not detected; grade 1, the thickness of bursal fluid $<5 \mathrm{~mm}$; and grade 2 , the thickness of bursal fluid $\geq 5 \mathrm{~mm}$. SSP tendon tear retraction was measured from the torn SSP tendon stump to the lateral aspect of the greater tuberosity on an oblique coronal MRI (T2-weighted imaging). SSC tendon tears were diagnosed on the basis of the axial and oblique sagittal T2-weighted MRI. A partial tear was diagnosed if high signal intensity was detected in the most proximal portion of the SSC tendon but did not involve the full thickness of the tendon. A complete tear was diagnosed if a detachment of SSC tendon insertion 
was detected. Cuff tears spreading to the middle facet on the oblique sagittal MRI (T2-weighted imaging) were defined as ISP tendon tears. The fatty infiltration of the SSC, SSP, and ISP muscles was assessed on an oblique sagittal MRI (T1-weighted imaging) according to the modified Goutallier classification using a slice of the outermost edge touching the spine and the body of the scapula $[13,14]$. Changes in these factors were analyzed in each group between initial MRI and repeat MRI.

\section{Statistical methods}

Chi-squared test was used to evaluate differences in the decreasing rate in bursal fluid accumulation and the progression rates of SSC, ISP tendon tears, and Goutallier classification in SSC, SSP, and ISP between the two groups. Mann-Whitney $U$ tests were used to investigate differences in the progression of SSP tendon retraction between the two groups. Logistic regression analysis was performed to investigate predictive factors for persistent pain on the initial MRI and factors associated with persisting pain after nonsurgical treatment on the repeat MRI. Odds ratios (ORs) and 95\% confidence intervals (CIs) were calculated. From the univariate logistic regression analysis, the variables that had a $P$ value of $<$ 0.05 were considered as potential variables. Multivariate logistic regression was performed in the next phase. $A P$ value of $<0.05$ was considered statistically significant.

\section{Results}

\section{Changes in the factors}

The changes in each factor are shown in Table 1. As bursal fluid accumulated in the pain group, one of four grade 0 shoulders increased to grade 1 . Of the 34 shoulders that were grade 1,4 shoulders decreased to grade 0 and 8 shoulders increased to grade 2 . Six of the 29 grade 2 shoulders decreased to grade 1 . As the bursal fluid in improvement group, of 6 shoulders that were grade 0,1 shoulder increased to grade 1 and 1 shoulder increased to grade 2 . Five of 20 grade 1 shoulders decreased to grade 0 . Of 15 shoulders that were grade 2, 4 shoulders decreased to grade 0 and 5 shoulders decreased to grade 1. The improvement group showed a significant decrease compared with the pain group in bursal fluid accumulation $(P<0.01)$. SSP tendon tear retraction progressed from $24.4 \pm 13.5 \mathrm{~mm}$ to $28.5 \pm 14.1 \mathrm{~mm}$ in pain group and from $17.1 \pm 13.8 \mathrm{~mm}$ to $21.2 \pm 14.4 \mathrm{~mm}$ in improvement group. The average progression of SSP tendon tear retraction was $4.1 \pm 5.4 \mathrm{~mm}$ in the pain group and $4.1 \pm 5.2 \mathrm{~mm}$ in the improvement group, and there was no significant difference between the two groups $(P$ $=0.90)$. With regard to SSC tendon tears, in the pain group, the progression rate of SSC tendon tears was $11.9 \%$. In the improvement group, the progression rate of SSC tendon tears was $2.4 \%$. There was no significant
Table 1 Changes in factors

\begin{tabular}{|c|c|c|c|c|}
\hline & \multicolumn{2}{|l|}{ Pain group } & \multicolumn{2}{|c|}{ Improvement group } \\
\hline & Initial MRI & Repeat MRI & Initial MRI & Repeat MRI \\
\hline \multicolumn{5}{|c|}{ Bursal fluid accumulation } \\
\hline Grade 0 & 4 & 7 & 6 & 13 \\
\hline Grade 1 & 34 & 29 & 20 & 21 \\
\hline Grade 2 & 29 & 31 & 15 & 7 \\
\hline \multicolumn{5}{|l|}{ SSP retraction } \\
\hline$(\mathrm{mm})$ & $24.4 \pm 13.5$ & $28.5 \pm 14.1$ & $17.1 \pm 13.8$ & $21.2 \pm 14.4$ \\
\hline \multicolumn{5}{|l|}{ SSC tendon tears } \\
\hline No tears & 26 & 20 & 29 & 28 \\
\hline Partial tears & 19 & 23 & 7 & 8 \\
\hline Complete tears & 22 & 29 & 5 & 5 \\
\hline \multicolumn{5}{|l|}{ ISP tendon tears } \\
\hline No tears & 41 & 33 & 33 & 30 \\
\hline Tears & 26 & 34 & 8 & 11 \\
\hline \multicolumn{5}{|c|}{ Goutallier classification in SSC } \\
\hline Grade 0 & 24 & 22 & 26 & 26 \\
\hline Grade 1 & 21 & 23 & 8 & 7 \\
\hline Grade 2 & 10 & 10 & 3 & 3 \\
\hline Grade 3 & 4 & 4 & 2 & 1 \\
\hline Grade 4 & 8 & 8 & 2 & 4 \\
\hline \multicolumn{5}{|c|}{ Goutallier classification in SSP } \\
\hline Grade 0 & 0 & 0 & 1 & 0 \\
\hline Grade 1 & 15 & 14 & 15 & 14 \\
\hline Grade 2 & 31 & 28 & 21 & 20 \\
\hline Grade 3 & 9 & 12 & 1 & 3 \\
\hline Grade 4 & 12 & 13 & 3 & 4 \\
\hline \multicolumn{5}{|c|}{ Goutallier classification in ISP } \\
\hline Grade 0 & 7 & 5 & 10 & 10 \\
\hline Grade 1 & 33 & 30 & 24 & 20 \\
\hline Grade 2 & 9 & 9 & 3 & 6 \\
\hline Grade 3 & 4 & 6 & 0 & 0 \\
\hline Grade 4 & 14 & 17 & 4 & 5 \\
\hline
\end{tabular}

$I S P$, infraspinatus; SSC, subscapularis; SSP, supraspinatus

difference in progression rate of SSC tendon tears between the two groups $(P=0.08)$. For ISP tendon tears, the progression rate of ISP tendon tears was $11.9 \%$ in the pain group, while in the improvement the progression rate was $7.3 \%$. There was no significant difference in progression rate of ISP tendon tears between the two groups $(P=0.44)$. In the Goutallier classification in SSC, the progression rate of the Goutallier classification for SSC was $3.0 \%$ in the pain group, while in the improvement group it was $7.3 \%$. No significant differences were seen for this parameter between the two groups $(P=$ 0.30 ). The progression rate according to the Goutallier classification for SSP in the pain group was $14.9 \%$, while 
in the improvement group it was $14.6 \%$. No significant difference in progression rate of Goutallier classification in SSP between the two groups was noted $(P=0.97)$. With regards to the Goutallier classification for ISP, in the pain group, the progression rate was $17.9 \%$, and in the improvement group, it was $12.2 \%$. No significant differences in the progression rate of the Goutallier classification in ISP between the two groups was noted $(P=0.43)$.

\section{Predictive factor for persistent pain in initial MRI}

For multivariate logistic regression analysis to investigate predictive factor for persistent pain in initial MRI, variables with $P<0.05$ in univariate models were selected (Table 2). Therefore, SSP tendon retraction, SSC tendon tears, ISP tendon tears, and Goutallier classification in SSC, SSP, and ISP were selected. On the multivariate logistic regression analysis, SSC tendon tears (OR, 4.48; 95\% CI, 1.14-16.0; $P=0.03$ ) on initial MRI were considered as predictive factor for persistent pain (Table 3).

\section{Factor associated with persisting pain after nonsurgical treatment in repeat MRI}

Multivariate logistic regression analysis was employed to investigate the factors associated with persisting pain after the nonsurgical treatment in repeat MRI. Variables with $P<0.05$ in univariate models were selected (Table 4). Therefore, bursal fluid, SSP tendon retraction, SSC tendon tears, ISP tendon tears and Goutallier classification in SSP, and ISP were selected. Multivariate logistic regression analysis found that bursal fluid (OR, 2.80; 95\% CI, 1.40-5.61; $P=0.04$ ) and SSC tendon tears (OR, 2.37; 95\% CI, $1.21-4.64 ; P=0.01$ ) on repeat MRI were significantly associated with persistent pain (Table 5).

\section{Discussion}

There are several reports of predictors of outcome of nonsurgical treatment for rotator cuff tears $[6,8,11,12]$. However, nonsurgical treatment outcome was defined as a success if surgical treatment was not required in most

Table 2 Univariate logistic regression analysis in initial MRI

\begin{tabular}{llll}
\hline Predictive factor for persistent pain & OR & $95 \% \mathrm{Cl}$ & $P$ value \\
\hline 1. Bursal fluid accumulation & 1.47 & $0.79-2.72$ & 0.224 \\
2. SSP tendon tear retraction & 1.04 & $1.01-1.08$ & $0.010^{*}$ \\
3. SSC tendon tears & 2.34 & $1.36-4.02$ & $0.002^{*}$ \\
4. ISP tendon tears & 2.62 & $1.05-6.53$ & $0.040^{*}$ \\
5. Goutallier classification in SSC & 1.50 & $1.05-2.15$ & $0.026^{*}$ \\
6. Goutallier classification in SSP & 1.83 & $1.15-2.90$ & $0.011^{*}$ \\
7. Goutallier classification in ISP & 1.58 & $1.10-2.27$ & $0.013^{*}$ \\
\hline
\end{tabular}

$\mathrm{Cl}$, confidence interval; ISP, infraspinatus; OR, odds ratio; SSC, subscapularis; SSP, supraspinatus

${ }^{*} P$ value $<0.05$
Table 3 Multivariate logistic regression analysis in initial MRI

\begin{tabular}{|c|c|c|c|}
\hline Predictive factor for persistent pain & OR & $95 \% \mathrm{Cl}$ & $P$ value \\
\hline 2. SSP tendon tear retraction & 1.00 & $0.96-1.05$ & 0.87 \\
\hline 3. SSC tendon tears & 4.28 & $1.14-16.0$ & $0.03^{*}$ \\
\hline 4. ISP tendon tears & 1.37 & $0.31-6.09$ & 0.68 \\
\hline 5. Goutallier classification in SSC & 0.54 & $0.24-1.23$ & 0.14 \\
\hline 6. Goutallier classification in SSP & 1.33 & $0.64-2.75$ & 0.45 \\
\hline 7. Goutallier classification in ISP & 1.05 & $0.56-1.99$ & 0.87 \\
\hline
\end{tabular}

previous studies. Strengths of our study include re-assessing via MRI patients who did not have surgery with more than a year of follow-up, and we compared patients that became asymptomatic by nonsurgical treatment with patients that pain persisted and nonsurgical treatment is continued.

There are a few reports comparing MRI findings in symptomatic and asymptomatic rotator cuff tears. Some reports showed that there was no difference $[15,16]$, others showed that there were significant associations between symptoms and tear size, positive tangent sign, and fatty degeneration [17]. It was often reported that symptoms of pain do not correlate with rotator cuff tear severity [18-20]. However, there are currently no reports to examine SSC tendon tears in previous studies, apart from a study conducted by Harris et al. who reported that involvement of the SSP, ISP, and SSC tendons was associated with a decreased American Shoulder and Elbow Surgeons score comparing isolated SSP tears in patients with symptomatic and traumatic full-thickness rotator cuff tears who are enrolled in a structured physical therapy program [19]. In our study, we evaluated factors associated with pain in nonsurgically treated SSP tendon tears by MRI. Bursal fluid accumulation, SSP tendon retraction, SSC tendon tears, ISP tendon tears, and Goutallier classification in SSC, SSP, and ISP were included as evaluation factors in the multivariate logistic

Table 4 Univariate logistic regression analysis in repeat MRI

\begin{tabular}{llll}
\hline Factor associated with persisting pain & OR & $95 \% \mathrm{Cl}$ & $P$ value \\
\hline 1. Bursal fluid accumulation & 3.17 & $1.69-5.94$ & $0.0003^{*}$ \\
2. SSP tendon tear retraction & 1.04 & $1.01-1.07$ & $0.013^{*}$ \\
3. SSC tendon tears & 2.81 & $1.60-4.92$ & $0.0003^{*}$ \\
4. ISP tendon tears & 2.81 & $1.21-6.51$ & $0.016^{*}$ \\
5. Goutallier classification in SSC & 1.39 & $1.00-1.94$ & 0.053 \\
6. Goutallier classification in SSP & 1.75 & $1.13-2.69$ & $0.012^{*}$ \\
7. Goutallier classification in ISP & 1.57 & $1.12-2.20$ & $0.0082^{*}$ \\
\hline
\end{tabular}

$C l$, confidence interval; ISP, infraspinatus; $O R$, odds ratio; SSC, subscapularis; $S S P$, supraspinatus

${ }^{*} P$ value $<0.05$ 
Table 5 Multivariate logistic regression analysis in repeat MRI

\begin{tabular}{llll}
\hline Factor associated with persisting pain & OR & $95 \% \mathrm{Cl}$ & $P$ value \\
\hline 1. Bursal fluid accumulation & 2.80 & $1.40-5.61$ & $0.04^{*}$ \\
2. SSP tendon tear retraction & 0.99 & $0.94-1.04$ & 0.75 \\
3. SSC tendon tears & 2.37 & $1.21-4.64$ & $0.01^{*}$ \\
4. ISP tendon tears & 1.78 & $0.44-7.18$ & 0.42 \\
6. Goutallier classification in SSP & 0.83 & $0.37-1.82$ & 0.64 \\
7. Goutallier classification in ISP & 1.13 & $0.64-2.00$ & 0.69
\end{tabular}

$C l$, confidence interval; ISP, infraspinatus; $O R$, odds ratio; SSC, subscapularis; SSP, supraspinatus

${ }^{*} P$ value $<0.05$

regression analysis. Consequentially, bursal fluid decreased when pain improved. This suggested the subcoracoid-subacromial-subdeltoid bursal fluid was associated with the presence of pain. However, bursal fluid could not be a predictive factor for persistent pain in the initial MRI. On the other hand, rotator cuff tears with the involvement of SSC tendon tears on initial MRI were considered as predictive factors for persistent pain.

The balance between the SSC muscle and the ISP and teres minor muscles is often referred to as the rotator cuff "transversal force couple." It generates stability in the glenohumeral joint by an antagonistic balance between the forces exerted in an anterior and posterior part [21]. This anterior-posterior force balance between the SSC and the ISP, and teres minor causes compression of the humeral head into the glenoid fossa in patients with isolated SSP tendon tears [22-24]. Even when there are irreparable rotator cuff tears, shoulder function can be preserved if there is a balance between important force couples $[25,26]$. Therefore, damage of transversal force couples is suggested as the cause of the correlation between SSC tendon tears and persistent pain. On the other hand, ISP tendon tears were not a factor associated with persistent pain in this study. This may be due to compensation by teres minor muscles. It has been reported that progression of ISP muscle atrophy induces compensatory hypertrophy of the teres minor muscles [27, 28].

The SSC has other crucial functions in the shoulder joint. The SSC stabilizes the long head of the biceps tendon. It was reported that most SSC tendon tears occurred on the most superior part and the articular side of the attachment of the humerus [29, 30]. Ide et al. reported that the SSC insertion to the humerus consisted of a proximal tendinous part and a distal muscular part in anatomical study [31]. Arai et al. reported that anatomically, the most superior part of the SSC tendon was attached to the upper margin of the lesser tuberosity and extended as a thin tendinous slip to the fovea capitis of the humerus [32]. The trochlea-like structure was composed of the superior-most insertion, the tendinous slip, and the lateral portion of the cranial part of intramuscular tendons supporting the long head of the biceps tendon. SSC tendon tears, involving injuries of the trochlea-like structure, causes instability and pathology of the long head of the biceps tendon [33, 34]. SSC tendon tears may induce lesion of the long head of biceps tendon and cause pain.

For the reasons stated above, in this study, SSC tendon tears may be associated with persistent pain for nonsurgically treated rotator cuff tears. Arthroscopic repair with use of a suture anchor technique has been reported to be a safe and effective procedure for the treatment of combined rotator cuff tears involving the SSC tendon [35]. It has also been demonstrated that improvement in functional outcome after arthroscopic repair of an SSC tendon tear is maintained long-term [36]. Therefore, if no effect is seen from nonsurgical treatment for rotator cuff tears with the involvement of SSC tendons, surgical repair can be considered.

\section{Limitations}

There were several limitations to this study. First, the number of cases included is small. Second, nonsurgical treatment was not standardized as the frequency of injection varied. Third, there is no scale for pain evaluation. Conditions requiring continued nonsurgical treatments such as steroids, hyaluronic acid injections, and/or anti-inflammatory analgesics were defined as persistent pain. Fourth, interpretations of MRI are not always accurate $[37,38]$. However, Adam et al. state that preoperative shoulder MRI scans interpreted by orthopedic surgeons via a systematic approach resulted in improved accuracy in diagnosing SSC tendon tears [39]. Yoshimura et al. focused on the anatomical structure of SSC and evaluated MRI findings of the most proximal portion of the SSC tendon on axial and oblique sagittal T2-weighted images [40]. Based on their report, SSC tendon tears were evaluated on MRI in this study.

\section{Conclusions}

We evaluated the factors associated with pain in nonsurgically treated rotator cuff tears by MRI. Bursal fluid accumulation decreased when pain improved, but the bursal fluid is not a reliable predictive factor for persistent pain in initial MRI. On the other hand, SSC tendon tears on initial and repeat MRI were significantly associated with persistent pain. Therefore, the involvement of SSC tendon tears may serve as a predictive factor in persistent pain. SSC function may be important since SSC contributes to "transversal force couple" and stabilizes the long head of the biceps tendon. When patients with rotator cuff tears including SSC tendon tears are treated nonsurgically, attention to the possibility of persistent pain should be given. 


\section{Abbreviations}

Cls: Confidence intervals; ETL: Echo train length; FOV: Field of view; ISP: Infraspinatus; MRI: Magnetic resonance imaging; ORs: Odds ratios; SSC: Subscapularis; SSP: Supraspinatus; TE: Echo time; TR: Repetition time

\section{Acknowledgements}

Not applicable.

\section{Funding}

No source of outside financial funding was used for this study.

\section{Availability of data and materials}

The datasets generated and analyzed during the current study are not publicly available due to Japanese personal information protection law, but are available from the corresponding author on reasonable request.

\section{Authors' contributions}

YN contributed to the design of the study, enrolment of patients, data gathering, analysis, interpretation, and writing of the manuscript. SY conducted the treatment of the patients and contributed to the interpretation and writing of the manuscript. YH contributed to data gathering and analysis. MO and NA supervised the study and critically revised the manuscript for important intellectual content. All authors have read and approved the manuscript.

\section{Ethics approval and consent to participate}

This article was approved by the Ethical Committee for Epidemiology of Hiroshima University Study Number Epi-734.

\section{Consent for publication}

Not applicable.

\section{Competing interests}

The authors declare that they have no competing interests.

\section{Publisher's Note}

Springer Nature remains neutral with regard to jurisdictional claims in published maps and institutional affiliations.

\section{Author details}

'Department of Orthopaedic Surgery, Chugoku Rosai Hospital, 1-5-1, Tagaya, Hiro, Kure City, Hiroshima 737-0193, Japan. ²Department of Orthopaedic Surgery, Hiroshima University, 1-2-3 Kasumi, Minami-ku, Hiroshima City, Hiroshima 734-8551, Japan. ${ }^{3}$ Department of Orthopaedic Surgery, Aichi Medical University, 1-1 Yazakokarimata, Nagakute City, Aichi 480-1195, Japan. ${ }^{4}$ Hiroshima University, 1-4-1 Kagamiyama, Higashi-hiroshima City, Hiroshima 739-8527, Japan. ${ }^{5}$ Department of Orthopaedic Surgery, Hiroshima University, 1-2-3 Kasumi, Minami-ku, Hiroshima City, Hiroshima 734-8551, Japan.

\section{Received: 1 January 2019 Accepted: 30 April 2019}

\section{Published online: 14 May 2019}

\section{References}

1. Minagawa H, Yamamoto N, Abe H, Fukuda M, Seki N, Kikuchi K, Kijima H, Itoi E. Prevalence of symptomatic and asymptomatic rotator cuff tears in the general population: From mass-screening in one village. J Orthop. 2013; 10(1):8-12.

2. Yamamoto A, Takagishi K, Kobayashi T, Shitara H, Osawa T. Factors involved in the presence of symptoms associated with rotator cuff tears: a comparison of asymptomatic and symptomatic rotator cuff tears in the general population. J Shoulder Elbow Surg. 2011;20(7):1133-7.

3. Oliva F, Piccirilli E, Bossa M, Via AG, Colombo A, Chillemi C, Gasparre G, Pellicciari L, Franceschetti E, Rugiero C, et al. I.S.Mu.L.T - Rotator Cuff Tears Guidelines. Muscles Ligaments Tendons J. 2015:5(4):227-63.

4. Abdul-Wahab TA, Betancourt JP, Hassan F, Thani SA, Choueiri H, Jain NB, Malanga GA, Murrell WD, Prasad A, Verborgt O. Initial treatment of complete rotator cuff tear and transition to surgical treatment: systematic review of the evidence. Muscles Ligaments Tendons J. 2016;6(1):35-47.

5. Kijima H, Minagawa H, Nishi T, Kikuchi K, Shimada Y. Long-term follow-up of cases of rotator cuff tear treated conservatively. J Shoulder Elbow Surg. 2012;21(4):491-4.
6. Tanaka M, Itoi E, Sato K, Hamada J, Hitachi S, Tojo Y, Honda M, Tabata S. Factors related to successful outcome of conservative treatment for rotator cuff tears. Ups J Med Sci. 2010;115(3):193-200.

7. Brown JT. Early assessment of supraspinatus tears; procaine infiltration as a guide to treatment. J Bone Joint Surg Br. 1949;31B(3):423-5.

8. Itoi E, Tabata S. Conservative treatment of rotator cuff tears. Clin Orthop Relat Res. 1992;275:165-73.

9. Samilson RL, Binder WF. Symptomatic full thickness tears of rotator cuff. An analysis of 292 shoulders in 276 patients. Orthop Clin North Am. 1975;6(2): 449-66.

10. Wolfgang GL. Surgical repair of tears of the rotator cuff of the shoulder. Factors influencing the result. J Bone Joint Surg Am. 1974;56(1):14-26.

11. Boorman RS, More KD, Hollinshead RM, Wiley JP, Brett K, Mohtadi NG, Nelson AA, Lo IK, Bryant D. The rotator cuff quality-of-life index predicts the outcome of nonoperative treatment of patients with a chronic rotator cuff tear. J Bone Joint Surg Am. 2014;96(22):1883-8.

12. Dunn WR, Kuhn JE, Sanders R, An Q, Baumgarten KM, Bishop JY, Brophy RH, Carey JL, Harrell F, Holloway BG, et al. 2013 Neer Award: predictors of failure of nonoperative treatment of chronic, symptomatic, full-thickness rotator cuff tears. J Shoulder Elbow Surg. 2016;25(8):1303-11.

13. Fuchs B, Weishaupt D, Zanetti M, Hodler J, Gerber C. Fatty degeneration of the muscles of the rotator cuff: assessment by computed tomography versus magnetic resonance imaging. J Shoulder Elbow Surg. 1999;8(6):599-605.

14. Goutallier D, Postel JM, Bernageau J, Lavau L, Voisin MC. Fatty muscle degeneration in cuff ruptures. Pre- and postoperative evaluation by CT scan Clin Orthop Relat Res. 1994:304:78-83.

15. Hodgson RJ, O'Connor PJ, Hensor EM, Barron D, Robinson P. Contrastenhanced MRI of the subdeltoid, subacromial bursa in painful and painless rotator cuff tears. Br J Radiol. 2012:85(1019):1482-7.

16. Hirano $Y$, Sashi R, Izumi J, Itoi E, Watarai J. Comparison of the MR findings on indirect MR arthrography in patients with rotator cuff tears with and without symptoms. Radiat Med. 2006;24(1):23-7.

17. Moosmayer S, Tariq R, Stiris MG, Smith HJ. MRI of symptomatic and asymptomatic full-thickness rotator cuff tears. A comparison of findings in 100 subjects. Acta Orthop. 2010;81(3):361-6.

18. Dunn WR, Kuhn JE, Sanders R, An Q, Baumgarten KM, Bishop JY, Brophy RH, Carey JL, Holloway GB, Jones GL, et al. Symptoms of pain do not correlate with rotator cuff tear severity: a cross-sectional study of 393 patients with a symptomatic atraumatic full-thickness rotator cuff tear. J Bone Joint Surg Am. 2014;96(10):793-800.

19. Harris JD, Pedroza A, Jones GL. Predictors of pain and function in patients with symptomatic, atraumatic full-thickness rotator cuff tears: a time-zero analysis of a prospective patient cohort enrolled in a structured physical therapy program. Am J Sports Med. 2012:40(2):359-66.

20. Wylie JD, Suter T, Potter MQ, Granger EK, Tashjian RZ. Mental Health Has a Stronger Association with Patient-Reported Shoulder Pain and Function Than Tear Size in Patients with Full-Thickness Rotator Cuff Tears. J Bone Joint Surg Am. 2016;98(4):251-6.

21. Thompson WO, Debski RE, Boardman ND 3rd, Taskiran E, Warner JJ, Fu FH, Woo SL. A biomechanical analysis of rotator cuff deficiency in a cadaveric model. Am J Sports Med. 1996;24(3):286-92.

22. Lippitt S, Matsen F. Mechanisms of glenohumeral joint stability. Clin Orthop Relat Res. 1993;291:20-8.

23. Karduna AR, Williams $G R$, Williams $J L$, lannotti JP. Kinematics of the glenohumeral joint: influences of muscle forces, ligamentous constraints, and articular geometry. J Orthop Res. 1996;14(6):986-93.

24. Bassett RW, Browne AO, Morrey BF, An KN. Glenohumeral muscle force and moment mechanics in a position of shoulder instability. J Biomech. 1990; 23(5):405-15.

25. Burkhart SS. Arthroscopic treatment of massive rotator cuff tears. Clinical results and biomechanical rationale. Clin Orthop Relat Res. 1991;267:45-56.

26. Burkhart SS. Fluoroscopic comparison of kinematic patterns in massive rotator cuff tears. A suspension bridge model. Clin Orthop Relat Res. 1992; 284:144-52.

27. Kikukawa K, Ide J, Kikuchi K, Morita M, Mizuta H, Ogata H. Hypertrophic changes of the teres minor muscle in rotator cuff tears: quantitative evaluation by magnetic resonance imaging. J Shoulder Elbow Surg. 2014; 23(12):1800-5

28. Kikukawa K, Ide J, Terakawa Y, Takada K, Morita M, Hashimoto K, Mizuta H. Hypertrophic teres minor restores shoulder strength and range of external 
rotation in posterosuperior rotator cuff tears. J Shoulder Elbow Surg. 2016; 25(11):1882-8.

29. Sakurai G, Ozaki J, Tomita Y, Kondo T, Tamai S. Incomplete tears of the subscapularis tendon associated with tears of the supraspinatus tendon: cadaveric and clinical studies. J Shoulder Elbow Surg. 1998;7(5):510-5.

30. Deutsch A, Altchek DW, Veltri DM, Potter HG, Warren RF. Traumatic tears of the subscapularis tendon. Clinical diagnosis, magnetic resonance imaging findings, and operative treatment. Am J Sports Med. 1997;25(1):13-22.

31. Ide J, Tokiyoshi A, Hirose J, Mizuta H. An anatomic study of the subscapularis insertion to the humerus: the subscapularis footprint. Arthroscopy. 2008;24(7):749-53.

32. Arai R, Mochizuki T, Yamaguchi K, Sugaya H, Kobayashi M, Nakamura T, Akita K. Functional anatomy of the superior glenohumeral and coracohumeral ligaments and the subscapularis tendon in view of stabilization of the long head of the biceps tendon. J Shoulder Elbow Surg. 2010;19(1):58-64

33. Arai R, Sugaya H, Mochizuki T, Nimura A, Moriishi J, Akita K. Subscapularis tendon tear: an anatomic and clinical investigation. Arthroscopy. 2008;24(9): 997-1004.

34. Godeneche A, Nove-Josserand L, Audebert S, Toussaint B, Denard PJ, French Society for A, Ladermann A. Relationship between subscapularis tears and injuries to the biceps pulley. Knee Surg Sports Traumatol Arthrosc. 2017; 25(7):2114-20

35. Ide J, Tokiyoshi A, Hirose J, Mizuta H. Arthroscopic repair of traumatic combined rotator cuff tears involving the subscapularis tendon. J Bone Joint Surg Am. 2007:89(11):2378-88

36. Denard PJ, Jiwani AZ, Ladermann A, Burkhart SS. Long-term outcome of a consecutive series of subscapularis tendon tears repaired arthroscopically. Arthroscopy. 2012;28(11):1587-91.

37. Adams CR, Schoolfield JD, Burkhart SS. Accuracy of preoperative magnetic resonance imaging in predicting a subscapularis tendon tear based on arthroscopy. Arthroscopy. 2010;26(11):1427-33.

38. Tung GA, Yoo DC, Levine SM, Brody JM, Green A. Subscapularis tendon tear: primary and associated signs on MRI. J Comput Assist Tomogr. 2001;25(3): $417-24$

39. Adams CR, Brady PC, Koo SS, Narbona P, Arrigoni P, Karnes GJ, Burkhart SS. A systematic approach for diagnosing subscapularis tendon tears with preoperative magnetic resonance imaging scans. Arthroscopy. 2012;28(11): 1592-600.

40. Yoshimura H, Komatsu S, Mochizuki T, Nimura A, Akita K, Arai R. Prediction of the subscapularis tendon tears on MRI. Katakansetsu. 2012;36:813-6.

Ready to submit your research? Choose BMC and benefit from:

- fast, convenient online submission

- thorough peer review by experienced researchers in your field

- rapid publication on acceptance

- support for research data, including large and complex data types

- gold Open Access which fosters wider collaboration and increased citations

- maximum visibility for your research: over $100 \mathrm{M}$ website views per year

At $\mathrm{BMC}$, research is always in progress.

Learn more biomedcentral.com/submissions 